\title{
Epidemiology and control strategies of novel coronavirus disease in the context of India
}

\author{
Abhishek Gupta \\ Department of Zoology, Chaudhary Charan Singh University, Meerut-250004 (U. P.), India \\ Alka Rani \\ Department of Zoology, Kumaun University, Nainital-263001 (Uttarakhand), India \\ Nisha Sogan \\ Indira Gandhi National Open University (IGNOU), New Delhi-110068, India \\ R. S. Sharma* \\ Indian Council of Medical Research, Ansari Nagar, New Delhi-110029, India \\ Bindu Sharma \\ Department of Zoology, Chaudhary Charan Singh University, Meerut-250004 (U. P.), India \\ *Corresponding author. Email: ranjandersharma@gmail.com
}

\section{How to Cite}

Gupta, A. et al. (2021). Epidemiology and control strategies of novel coronavirus disease in the context of India. Journal of Applied and Natural Science, 13(1): 210 - 219. https://doi.org/10.31018/jans.v13i1.2517

\begin{abstract}
An outbreak of coronavirus disease (COVID-19) occurred for the first time in Wuhan, China which spread as a pandemic to various countries of the world, resulting in high morbidity and mortality. Death toll in India on $8^{\text {th }}$ February 2021 was $1,55,080$. India had implemented steps such as lockdown and advised social distancing, washing of hands, and wearing masks to reduce the burden of Covid-19. This review discusses the epidemiological features, the population at risk and control strategies of novel coronavirus disease in India. The data was collected from various sources on individual details of Covid-19 cases, population density and affluence percentage from the literature studied. The data was used to analyse the susceptibility of the population to this disease. It was found that Indian males, age group 20 to 40 (based on morbidity) and above 60 (based on mortality) were at high risk. The authors compiled epidemiology, management and control strategies of covid-19 in India. Therefore, because of various early implementations, India has managed the disease well earlier, but in the current scenario (30 Nov 2020) morbidity and mortality have been at peak. Immunization of frontline workers started on $16^{\text {th }}$ January 2021 . Initially, $7,017,411$ doses of Covishield and Covaxin vaccines have been given by $10^{\text {th }}$ February 2021 . Thus, the existing strategies like proper diagnosis, treatment, and successful implementation of vaccine inoculation will reduce covid-19 burden and may lead to normalcy.
\end{abstract}

\section{INTRODUCTION}

Coronavirus has recently emerged as SARS-CoV-2 (Severe Acute Respiratory Syndrome Corona Virus), causing great despair worldwide. As per the World Health Organization, total 10,838,194 confirmed cases of Covid-19 and 1,55,080 deaths were reported in India, as on 8 February, 2021 (WHO, India Situation Report, 54). Most affected states in India were Maharashtra, Karnataka, Andhra Pradesh, Tamil Nadu, Kerala, and Delhi (MOHFW, 2020). The mitigation methods included screening of symptomatic cases and containment of asymptomatic cases which were coming through air travel and cases due to contact with the infected ones (MOHFW, 2020). The same was also recommended by a study set when the cases in India were merely 3 , modelled to find the strategies to work towards the outbreak (Mandal et al., 2020).

There were several instances earlier too where members of Coronaviridae family has caused diseases like SARS-CoV in 2002 and MERS-CoV (Middle East Respiratory Syndrome coronavirus) in 2012 (Hilgenfeld and Peiris, 2013; Lu et al., 2015). Even earlier than SARS and MERS-CoV, coronavirus was responsible for respiratory infections. Human coronavirus (HCoV) was mentioned in earlier studies on infants, children in Indian states with fewer than $5 \%$ morbidity while studying respiratory pathogens (Malhotra et al., 2016; Sonawane et al., 2019). Coronavirus was also reported from domestic and wild animals of Indian states like Uttar 
Pradesh (Rai et al., 2011), Orissa (Behera et al., 2015), Haryana (Agnihotri et al., 2018) and others (Hansa et al., 2012a, b).

Novel Coronavirus ( $\mathrm{n}-\mathrm{Cov}$ ) has highly adapted strains as a result of genetic recombination and mutation (Lu et al., 2020). Being prevalent in diverse animals like bats, camels, cats, rodents etc. surrounding humans, it can be easily transmitted to humans (Ye et al., 2020). The SARS-CoV-2 (originated in China) is spreading faster than SARS-CoV and MERS-CoV with less mortality and high recovery (Chen, 2020). We have analysed population at risk and updated on the newly emerged coronavirus situation in India through epidemiology, on-going treatment, and control strategies.

\section{METHODS}

We searched for keywords "Covid-19", "SARS-CoV-2", "coronavirus India" on Pubmed, Google scholar and Web of Knowledge. We also went through news articles and situation reports of the World Health Organization, Advisory of Indian Council of Medical Research, Delhi and Ministry of Health and Family Welfare for information on the pandemic. Data on individual level Covid -19 cases in India from 30th January 2020 till $26^{\text {th }}$ April 2020 were obtained from Kaggle (https:// www.kaggle.com/sudalairajkumar/covid19-in-india).

WHO, Corona tracker India, census, IDSP (Integrated Diseases Surveillance Program) and worldometer websites were also referred to wherever pertinent. Association of Covid-19 cases and deaths for the population at risk was conducted using Chi-square test at $p$-value 0.05 . For all statistical test, MS excel 2013 (15.0.5172.1000) was used.

\section{About 2019-nCoV}

Coronavirus belongs to family Coronaviridae and order Nidovirales. This family has four genera, of which SARS-CoV and n-CoV-19 belong to genera Betacoronavirus, subgenera Sarbecovirus. Till now, seven coronaviruses from humans were identified. These are common human CoVs like HCoV-OC43, HcoV-HKU1, HcoV -229E, HCoV-NL63 and others like SARS-CoV, SARSCoV-2, and MERS-CoV. Except for HCoV-229E, and HCoV-NL63 (belonging to alphaCoV) all others belong to betaCoV (Zhu et al., 2020; Zhang et al., 2020). In India, several investigations reported coronavirus to cause respiratory diseases in humans. Four coronaviruses, namely HKU1, NL63, 229E and OC43 were found among humans earlier (Singhal, 2020). In 20022003, a new coronavirus designated as severe acute respiratory syndrome coronavirus emerged in China and Hong Kong with $11 \%$ mortality (Chan Yeung and $\mathrm{Xu}, 2003)$. Again in 2012, MERS-CoV appeared with a fatality rate of $34 \%$ (Memish et al., 2013). In 2019, SARS-CoV-2 appeared in the Wuhan city, Hubei prov- ince of China. This disease spread to other countries through the migration of population during Chinese New Year (Zhou et al., 2020; Jiang and Luo, 2020).

The preliminary phylogenetic analysis reported snakes to be its natural hosts, but this hypothesis was rejected (Zhang et al., 2020). Later, researchers identified bat as its host as it was nearest to Bat SARS-like CoVs (Bat-SLCoVs, MG772933 and MG772934) in phylogenetic analysis (Guo et al., 2020; Malik et al., 2020). It shares $80 \%$ and $50 \%$ genetic sequence resemblance to SARS-CoV and MERS-CoV, respectively. Both SARS-CoV and MERS-CoV transmission initiated from bats and passed on to humans via an intermediate host like palm civet cats in case of SARS-CoV and camels in case of MERS-CoV (Lu et al., 2020; Ye et al., 2020). It is suggested that new coronavirus (2019-nCoV) is most closely related with the BatCoV RaTG13 discovered in bats from Yunnan Province hence originated from the bat (Parakevis et al., 2020; Dhama et al., 2020). The intermediary animal responsible for the transmission of $\mathrm{nCoV}-19$ from the bat is still unidentified, snakes and pangolins suspected to play as intermediate (Yadav et al., 2020). Covid-19 is still under the preliminary stage of research and more insight is expected to its origin.

\section{Epidemiology of Covid-19 in India}

The emergence of new coronavirus was detected in China on January 7, 2020. After two months i.e., on $11^{\text {th }}$ March 2020, WHO declared Novel Coronavirus outbreak as a pandemic. On 22 March 2020, first lockdown and restriction on international travel was imposed. After the initial three confirmed cases recorded from Kerala in India $\left(30^{\text {th }}\right.$ January, 2020) with travel history from Wuhan, this viral disease had numerous cases. Fig. 1 (data till $26^{\text {th }}$ April as restriction on travel within and outside India was imposed) shows that travellers were mainly from Arab countries (Dubai, UAE, Iran, and Abu Dhabi) followed by European countries (maximum from Italy). Covid-19 infected travellers within India were also found with maximum contribution from Delhi and Maharashtra (others are Kerala, Tamil Nadu, Madhya Pradesh, West Bengal, Gujarat, and Uttar Pradesh). By 26th April 2020, only $5.18 \%$ cases had travelled outside India and others were either having a travel history within India or were close contact of the infected travellers. Hence, population movement possesses a major role in the progress of Covid19 disease within and across countries. Metropolitan cities like Delhi, Mumbai, Thrissur, and Chennai were the majorly affected areas as they are well connected by air travel to other infected countries (Wadhawan et al., 2020, Sardar et al., 2020).

As on 8 February 2021, the numbers of Covid-19 positive cases in India were 10, 847,790 with deaths being 155,080 . Daily increase in a number of COVID-19 cas- 


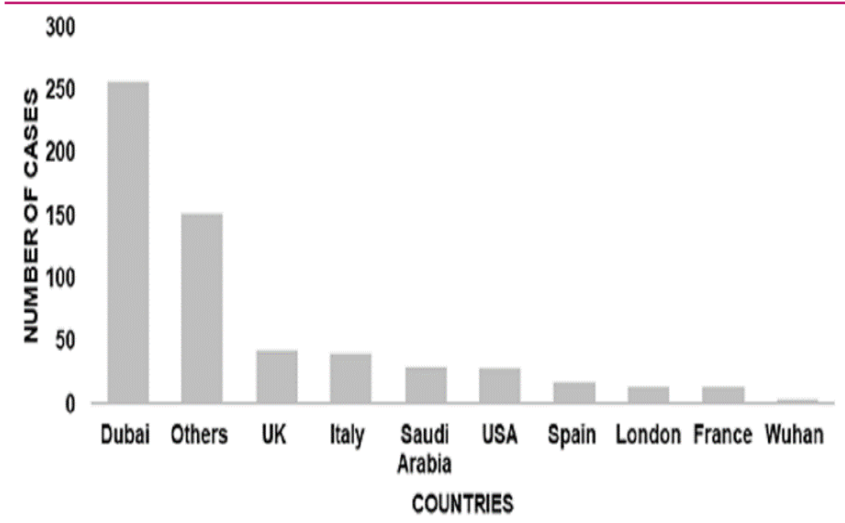

Fig. 1. Cases with travel history outside India (till travel disruptions on 22 March 2020). Source: https:// www.kaggle.com/sudalairajkumar/covid19-in-india)

es indicate $>500$ cases per day following April, 1, 2020 $>1000$ cases per day following April 20, 2020, > 2000 cases per day May 1, 2020, >20,000 cases per day from June 30 onwards. Maharashtra, Andhra Pradesh, Kerala, Karnataka, Tamil Nadu, and Delhi were the worst affected states. Based on the number of novel coronavirus cases districts were classified into a hotspot (as on $1^{\text {st }}$ May, 2020) which were marked as red zone (where a large number of positive cases were reported), non-hotspots districts or orange zone (recorded lesser number of positive cases), and green zone (where no fresh cases have been reported for some time). Delhi (100\% hotspots) and Maharashtra $(68.42 \%)$ have the largest number of hotspots on $1^{\text {st }}$ May, 2020. The percentage of hotspots decreased for Maharashtra (38.89\%) while remained same for Delhi (100\%) by $31^{\text {st }}$ December 2020 (Fig. 2).

Earlier reports show about $21 \%$ healthcare workers were affected during SARS outbreak. In India owing to COVID-19, 25 healthcare workers containing Doctors, nurses, compounders and other hospital staff were infected since the appearance of the first case, i.e., in 75 days (till $26^{\text {th }}$ April 2020). The shocking report of Bhilwara, Rajasthan had 15/19 cases of medical practitioners showing the vulnerability of health care professionals to the Covid-19 (Parikh et al., 2020). These data showed that healthcare workers are at high risk.

Data showed all ages to be susceptible to maximum cases from the age group of 21-40 years (46\%). Largest numbers of cases were from the age group 21-40 (44 \% on $26^{\text {th }}$ April, 2020 and $48 \%$ on $15^{\text {th }}$ February 2021) (Fig. 4). The mortality rate was estimated to be $0.27 \%$. The association of prevalence of novel coronavirus disease with age was also found significant by chi -square test at $p<0.05 \quad\left(\mathrm{df}=4, \quad x^{2}\right.$ statistic=94.75, $x 2_{\text {crtical }}=9.488$, alpha $=0.05 \%, p$-value is $<0.00001$ ).

The data (till 14th April 2020, India) analysis showed males $\left(\mathrm{df}=4, \mathrm{x}^{2}\right.$ statistic $=581.97, \mathrm{p}$-value $<0.00001$, significant at $p<0.05$ ) to be more susceptible as approximately $70 \%$ males showed morbidity and mortality with Covid-19 as compared to females $\left(\mathrm{df}=4, \mathrm{x}^{2}\right.$ statistic $=23.56$, $p$-value $=0.023361$, significant at $p<0.05$ ) (Table 1). This is similar to the case of Italy $(71 \%)$ and Spain (twice to a female) where more men were found susceptible (more died as compared to women) (Bakrania et al., 2020). The data at different times (6 April, 21 July, 4 August, 11 August and 1st September 2020) showed that males are having higher number of cases compared to females (Fig. 3).

\section{Role of social distancing}

Social distancing to reduce contact was suggested to prevent virus transmission (Bai, 2020). Social distancing is based on the principle of decreasing the basic reproductive number. Studies on basic reproductive number $\left(R_{0}\right)$ were done by many authors. For example, the importance of feasibility of controlling the outbreak in a country shows the effectiveness of isolation of a case to control Covid-19 within 3 months, if $R_{0}$ is 2.5 and transmission $15 \%$. The probability of transmission becomes higher with the longer period $\left(R_{0}\right.$ more than 2.5) as it requires a large number of contacts need to be traced and isolated which might not be possible (Hellewell et al., 2020). For slowing down the spread of Covid-19, less than $63 \%$ of social distancing is required (Jha et al., 2020). Swot analysis indicated the effectiveness of social distancing based on $\mathrm{R}_{0}$ showed failure in implementation on the part of the public like religious gatherings (case of Tablighi Jamaat) and migrant workers travel (Davey et al., 2020; Thurackal et al., 2020). The quarantine of positive and suspected cases and social distancing can slow the spread of novel coronavirus if executed properly. However, to stop it completely, antivirals and vaccines are necessary.

\section{Role of wearing masks}

The practice of wearing masks has been followed for preventing the spread of infectious diseases like influenza H1N1. Covid -19 patients release aerosols during exhalation, which can be spread to other people around them. Thus, using masks can impact turbulent gas cloud formation and can filter viral particles. It is reported that wearing the mask can reduce the viral reproduction number in the population (Cavanagh and Wambier, 2020; Li et al., 2020a, b; Lotfinejad et al., 2020).

Studies indicate that the virus is exhaled during talking and breathing. These aerosols contain viral load, which was detected to less than three hours as observed in human respiratory samples. Surgical masks can only prevent large sized droplets and sprays. The effectiveness of surgical masks and $\mathrm{N}-95$ respirators to protect against SARS-CoV-2 was found similar. The recent report of asymptomatic patients being a carrier of this virus has made the universal wearing of masks essential (Rundle et al., 2020; Roy et al., 2020) 
Percentage of Hotspots as on 3 May 2020

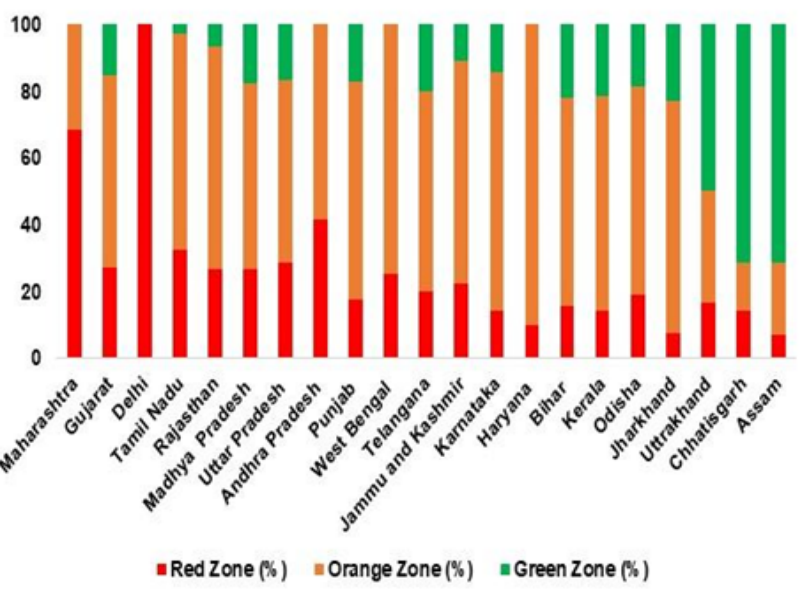

Percentage of hotspots as on 31st December 2020

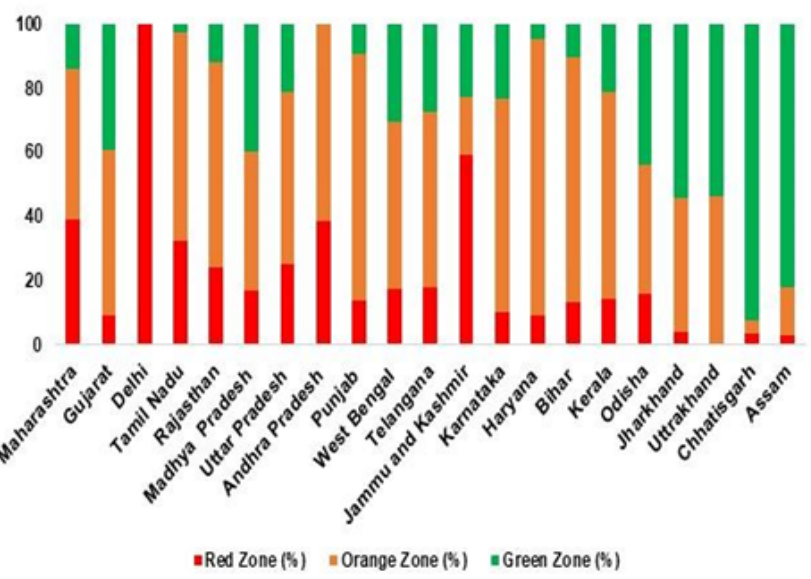

Fig. 2. Comparison of hotspots (red zone with other zones) from May 3, 2020 to December 31, 2020 in different states of India. (Source:https://www.kaggle.com/sudalairajkumar/covid19-in-india/; https://www.oneindia.com/coronavirus-affected -cities-districts-in-india)

\section{Role of washing hands}

Washing of hands with soap for an average of 20 seconds and alcohol-based sanitizer have been reported as the effective methods to reduce transmission of Covid-19 (Roy et al., 2020). These are low-cost method that can denature the virus by acting on the envelope protein. However, some studies reported damage to skin on frequent washing of hands which creates a route of entry for Covid-19 (Rundle et al., 2020; Marwah and Marwah, 2020). It can also cause pathophysiological changes, excessive skin dryness and several types of allergies of the skin. Yan et al. (2020) suggested the use of creams/moisturising after washing of hands and use of quality sanitizers. Creams/ moisturisers containing humectants with occlusive emollients acts as skin barrier and attracts water as well as prevent water loss thus moisturize skin (Beiu et al., 2020; Esposito et al., 2020).

\section{Demographical changes by urbanization impacting} novel corona virus transmission

Urbanization and population movement have caused the advancement of this virus within and across countries. The emergence of novel coronavirus occurred in China in December 2020, but spread to Japan, South Korea and Thailand by air travel by January 2020 . Once this virus entered a country, population density played its role in its transmission (Bhatia and Devulapalli, 2020). India has 5 megacities which are projected to 10 by 2030 (UNDESA, 2018). Cities with a large number of people accumulated in small area, especially slums are more prone to Covid-19 infection. People residing in the urban cities are more likely to infect with Covid-19, as their respiratory system is affected by the pollution and make them easy prey (Kaneda and Greenbaum, 2020; Wu et al., 2020).

When some randomly selected districts were compared using population density, affluence per cent, and Covid19 cases and deaths, a significant relationship was found as metropolitan cities like Bangalore, Mumbai, Chennai were most affected (Fig. 5). District wise comparison of affluence with a number of cases showed most of the red zone districts (districts with a large number of cases) are more affluent than green and orange ones. The population density and affluence percentage were further analysed by correlating with Covid-19 cases and deaths using Pearson's Coefficient. It was found that population density has a higher influence on Covid19 cases $(0.28, p>0.01)$ and deaths $(0.59, p>0.01)$ as compared to affluence (Fig. 6). Population density and type of zone were not found related to each other significantly (at $p<0.05)$ by Chi-square test $\left(x^{2}\right.$ statistic $=2.0773, p$-value $\left.=0.721539\right)$. This may be due to the fact that affluence is also influencing Covid19 cases in the three zones. Thus, Covid-19 cases in districts of India are influenced by population density as well as affluence. Neither affluence nor population density is singly acting as a variable affecting Covid-19

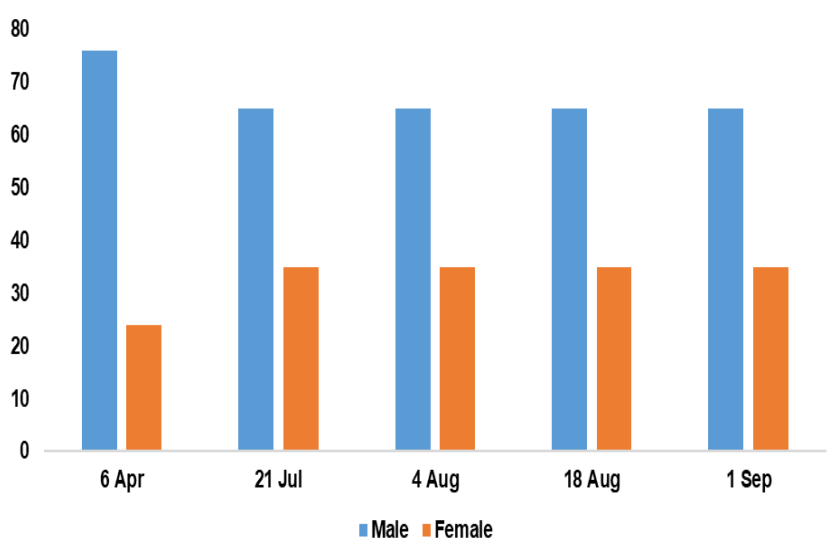

Fig. 3. Change in Covid-19 viral disease cases by Gender (Male/Female) from January 6 April, 2020 to 1 September, 2020 (Source: Kaggle.com/IDSP). 

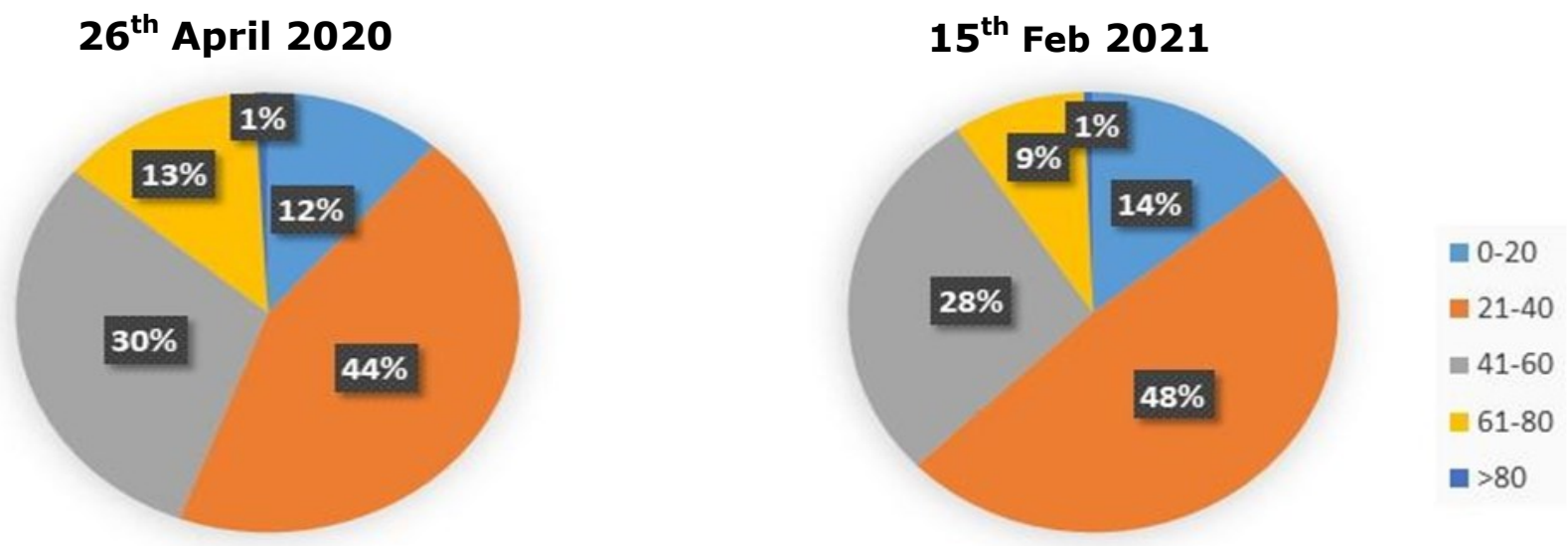

Fig. 4. Agewise comparison of coronavirus cases in India in ten months duration.(Source: Kaggle.com/IDSP $15^{\text {th }}$ Feb 2021)

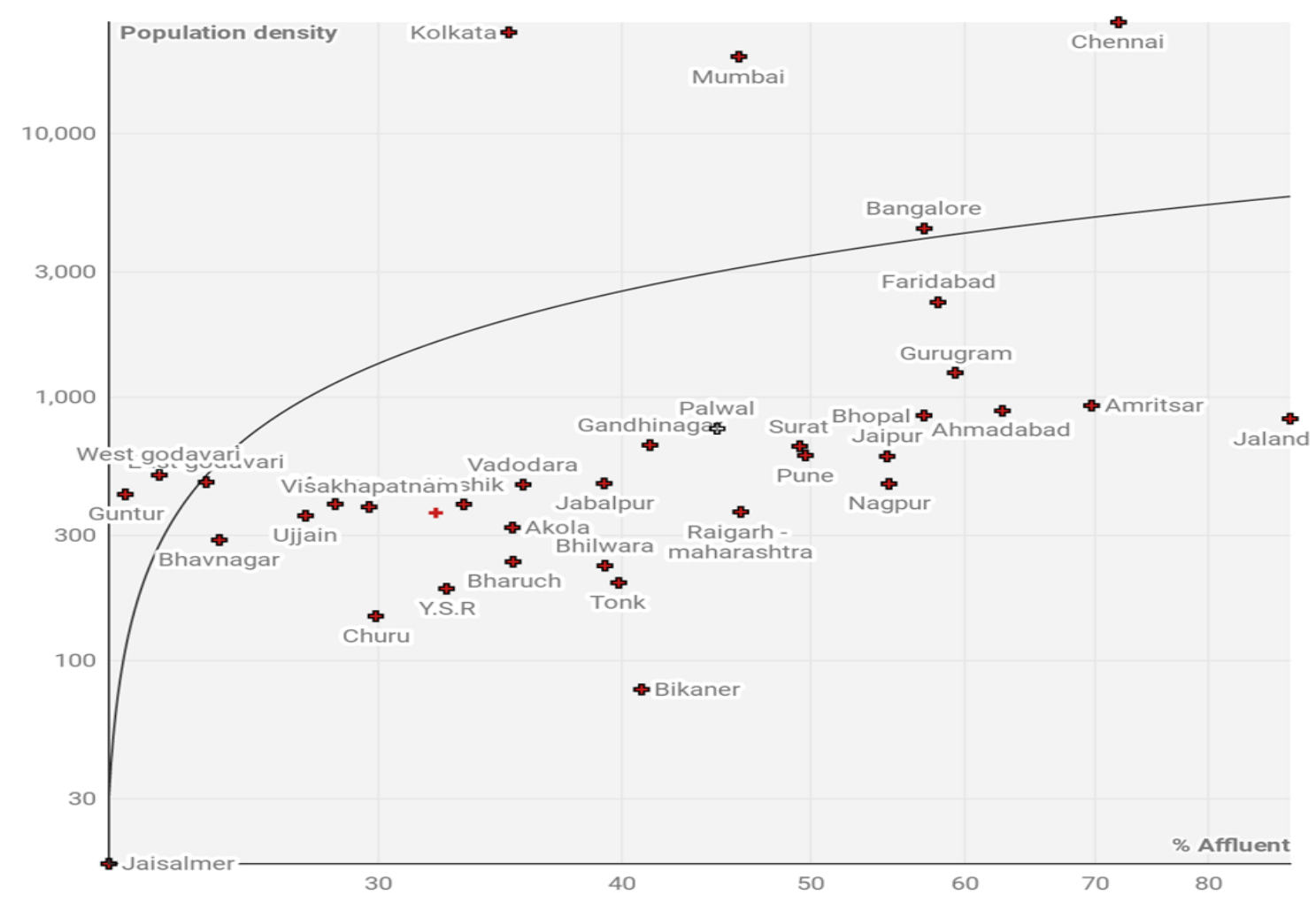

Fig. 5. Relationship of population density and affluence percentage of some of the selected districts with novel coronavirus disease, i.e., cases and deaths.

cases. Therefore, highly affluent districts with high population density are at higher risk of novel coronavirus disease. More urbanized, densely packed and prosperous districts with migrants are more vulnerable to novel coronavirus (Bhatia and Devulapalli,2020).

\section{Testing protocol of the Covid-19}

Timely management of coronavirus disease requires accurate laboratory testing for detecting ILI cases i.e., Influenza-Like Illness cases (those with acute respiratory infection, fever $>38^{\circ} \mathrm{C}$ and cough) and asymptomatic cases. Some laboratory tests identify the genetic material (e.g., Real-Time Polymerase Chain Reaction) while other specific antibodies to SARS-CoV-2 (e.g., Rapid Antigen Test). RTPCR (Real-Time Polymerase Chain Reaction) is the gold standard that requires specialized laboratory set up. It can accurately detect Covid-19 virus hence recommended as a confirmatory test.

Point of care (POC) diagnostics have been developed, which are rapid tests like Rapid Antigen Test (RAT), allowing testing even outside the laboratory. Although used for detecting SARS-CoV-2 yet can be validated 


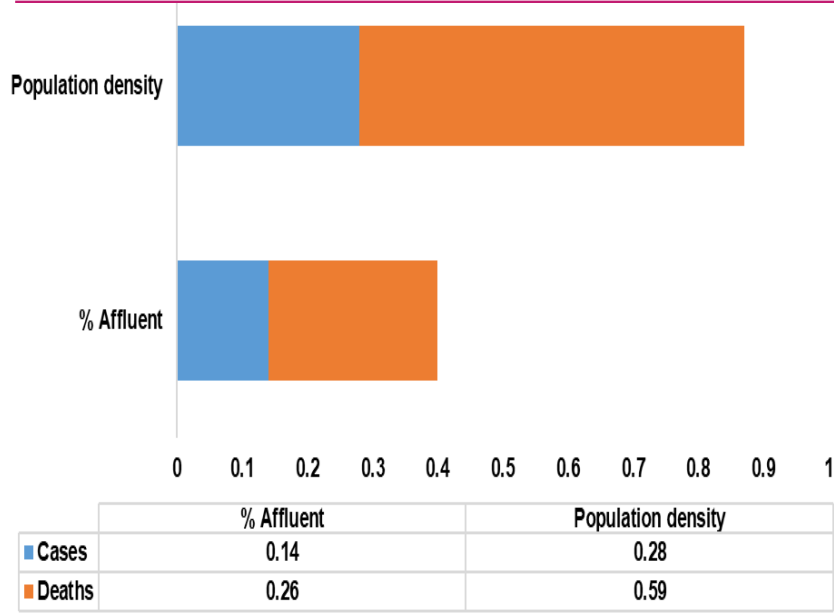

Fig. 6. Pearson's correlation analysis of the population density and affluence percentage with Covid-19 cases and deaths using Pearson's coefficient.

only after confirmation by RTPCR. Cartridge Based Nucleic Acid Amplification Test (CBNAAT) like TrueNaT and Cepheid Xpert Xpress SARS-CoV-2 are in use for testing in India (ICMR, 2020a). TrueNat has three types of assays i.e., TrueNat Beta CoV E gene screening assay, TrueNat SARS CoV2 RdRp gene confirmatory test and TrueNat Covid-19 multiplex assay. First samples are screened for $E$ gene using the first assay. Negative results considered to be true negative while positive samples go through RdRp gene confirmatory test and if positive are true positives. Multiplex Assay comprises both screening (E gene) and confirmatory (Orf1a) in a single test. No RTPCR confirmation is required after TrueNat Assay. As per ICMR advisories, symptomatic (ILI symptoms) cases, high risk and direct contact asymptomatic cases (including elderly $>65$ years in containment zones having comorbidities) should be tested with RAT and RT-PCR, TrueNat or CBNAAT. RAT is a test of priority in containment areas while RT-PCR in non-containment areas (exept for asymptomatic elders ageing> 65years). Single RTPCR/TrueNaT/CBNAAT/RAT test if positive, considered confirmatory (ICMR advisory version IV, dated $4^{\text {th }}$ September, 2020). Convalescent Plasma therapy was earlier considered promising. This therapy has been used for some Covid-19 patients in Delhi, Rajasthan, Punjab and Maharashtra and has shown promising results. ICMR has now specified that this therapy may not be effective against Covid-19 disease. This therapy only works when convalescent plasma has a high concentration of specific antibody against this disease or else is not beneficial (Chen et al., 2020). CRISPR SARS-CoV-2 test is a CRISR-Cas9 based technology recently approved by ICMR. This requires biosafety (BSL-2 level) precautions and uses a Thermal Cycler. It is said that no RTPCR confirmation is required in this test (ICMR, 2020a).

\section{Clinical features of Covid-19 infection}

Through studying the infection pattern of a novel coronavirus, the Centre for Disease Control and Prevention, USA recommended the incubation period of novel coronavirus of 14 days. However, for mildly symptomatic and asymptomatic cases, the infection may be earlier than this incubation period (Lauer et al., 2020; Li et al., 2020). The common symptoms include fever, dry cough, fatigue, sore throat, nasal congestion, muscle soreness, respiratory distress; and others like dyspnea, myalgia or arthralgia, sputum production, diarrhoea, nausea or vomiting, lymphopenia, haemoptysis and loss of taste and smell. Severe cases may have pneumonia and/or multi-organ failure in severe patients. The multi-organ dysfunction is characterized by acute lung failure, acute liver failure, acute kidney injury, cardiovascular disease as well as a wide spectrum of haematological abnormalities and neurological disorders. A study on 21 patients from a tertiary care centre in India exhibited $57.1 \%$ of the patients to have the common clinical symptoms-fever $(42.9 \%)$, cough $(42.9 \%)$, sore throat $(23.8 \%)$, headache $(13.6 \%)$, dyspnea $(4.8 \%)$ and patients $(68.3 \%)$. They had also reported about $33.3 \%$ to have an only loss of smell, while about $23.3 \%$ with an impaired taste only, and $11.7 \%$ of covid-19 infected patients had impaired taste and smell (Wang et al., 2020a). Occasionally the reason for the death of Covid19 cases of $>60$ years age is their underlying chronic medical conditions (lung disease, asthma, liver disease, cancer, renal disease, immune-compromising conditions) (Wang et al., 2020b). The viral load in severe cases of covid-19 is higher around 60 times than in mild cases. In mild cases, early viral clearance was also found when tested with RT-PCR (Reverse transcriptase Polymerase Chain Reaction). Since negative RT-PCR results were found positive by chest CT scan, hence it is recommended for negative RT-PCR cases (Fang et al., 2020; Liu et al., 2020). Since no vaccine or drugs have been discovered, therefore, treatment is symptomatic and supportive through antiviral and antiinflammatory treatment (Jiang et al., 2020).

\section{Vaccination programme}

Even though strong measures are being taken in diagnosis and treatment of Covid-19, vaccine is the only long-term solution to break the chain of transmission. As of December 2020, 274 vaccine candidates in different stages of development. Since the number of vaccines available will be lesser than the population of India, the Government has strategised the population with priority of vaccination. Based on that, vaccine is being offered to healthcare workers first, then population above 50 years of age, followed by the population below 50 years with co-morbidities and finally remaining population. Multiple vaccines are under develop- 
ment through one of the following techniques i.e., virus vaccines (using the whole virus in weakened or inactivated form), viral vector vaccines (genetically engineered coronavirus proteins are produced), nucleic acid vaccines (DNA or RNA), Protein-based vaccines (protein fragments or coronavirus is used). In December, 2020, 6 vaccines were under clinical trials. These are Covishield (Chimpanzee Adenovirus), Covaxin (Inactivated Virus), ZyCoV-D (DNA vaccine), Sputnik V (Human Adenovirus vaccine), NVX-CoV2373 (Protein Subunit) and Recombinant Protein Antigen based vaccine (Tregoning et al., 2020; ICMR (2020a, b).

Two vaccines candidates from Bharat Biotech and Zydus Cadila were under advance development (Dutta, 2020). Out of these, Covaxin has been given emergency approval and this was developed by Bharat Biotech in collaboration with the Indian Council of Medical Research (ICMR), New Delhi and National Institute of Virology (NIV), Pune. It was under phase 3 human trial when ICMR in India approved it. The Covishield vaccine was prepared by Serum Institute of India, Pune, which has partnered with British pharmaceutical company Astra Zeneca. The covishield vaccine has been approved in UK and based on that given approval in India too. Vaccination started on January 16, 2021 with the highest number of people vaccinated on day 1. However, after vaccination, several adverse events (about 580) were reported, including two deaths (a 52year-old in Moradabad and a 42-year-old in Karnataka (Soutik, 2020; Manavi, 2021).

\section{Future challenges}

Transmission can also occur via touching infected surfaces like inanimate objects. Coronavirus can survive in the air as aerosol droplets for several hours, in water, sewage and also in faecal samples (SARS-CoV). Hence, for the control of transmission, it is essential to estimate transmissibility. The reinfection in recovered patients and asymptomatic cases which can spread the virus to their contacts has turned into a challenge. Thus, further investigations are desired to understand the possibility of reinfection with this new coronavirus (Lan et al., 2020). Younger population (< 15 years) infected with Covid-19 are most prone to be asymptomatic (Bai et al., 2020).

The effect of environmental factors like temperature, humidity and wind speed showed almost negligible to moderate influence as studied in China and Italy (Bhattacharjee, 2020). Less influence of warm and humid climate on transmission was also observed, but the popular belief of ending coronavirus with the onset of the summer season was thus rejected (Mecenas et al., 2020). It can also persist in environmental media like sewage, water and faecal samples. There is an urgent need to study other environmental parameters like dust, particulate matter etc., for Covid-19 survival.
The effective means of spreading pathogens like viruses between humans and wildlife is vectors like mosquitoes. The emergence of Zika virus transmitted by $A e-$ des exemplifies the evolution and risks from viral pathogens (Singer, 2020). Several investigations showed the potential of nidoviruses to be transmitted by mosquitoes. For example, a study found CAVV (CAVV, coronavirus-like) isolated from Culex, Aedes, and Anopheles, with the most frequent being Culex (Junglen et al., 2009). Two nidoviruses, Cavally virus (CavV) and Nam Dinh virus (NDiV) were isolated from mosquitoes. "DakNong virus (DKNV)," was isolated from Culex tritaeniorhynchus Giles (Diptera: Culicidae) in Vietnam with genome size similar to Cavally virus (CavV) and Nam Dinh virus (NDiV) (Kuwata et al., 2013). Presence of RNA transcripts/GE in M-DBSs of ZIKAV, and MERS -CoV in An. gambiae shows its potential (Fauver et al., 2017). These studies indicated the potential of mosquitoes to transmit viruses. Since strains of coronavirus showed high replication fidelity and adaptability hence may evolve to spread infection by vectors like mosquitoes.

Several drugs and vaccines are under trial. Drugs like Umifenovir, MW Sepsivac are drugs working well under trial. Covaxin and Covishield have been given emergency approval and is currently under usage for inoculation and giving promising results. Other vaccines like ZyCoV-D, Biological E's novel Covid-19 vaccine and Sputinik are the vaccines currently under trial (Naik et al., 2020). Vaccines require more attention towards the elderly as weaker immune response will be induced in them. The drugs and vaccines under trial, if approved, may help us to respond further against Covid-19 pandemic.

\section{Conclusion}

Covid-19 pandemic requires strict vigilance, tracking, quarantine. Social distancing, wearing of masks and washing of hands have also been advised and had proved fruitful. This study found that Arab countries were the highest contributors to India's early Covid-19 cases through travellers. Metropolitan cities like Delhi, Mumbai, Pune, Chennai, Thrissur, Kozhikode, Thiruvananthapuram, etc. with more transport within and outside India were most responsible for transmission in India. Affluence and population density together act as factors impacting covid-19 cases. This is because the population from affluent areas travelled outside India and brought the virus with them. Once they came in contact with the virus individuals of affluent districts spread the virus to others which were transmitted more with densely populated areas. Indian males, age group 21 to 40 (in case of morbidity) and $>60$ (in case of mortality) were found to be more susceptible to Covid-19 disease. Two vaccines, i.e., Covishield and Covaxin 
have been given emergency approval and are currently being inoculated to frontline workers. Thus, vaccines are a promising way of reducing Covid-19 transmission and soon, their results can be seen as a reduction in the number of cases. Further research on the role of environmental factors, reinfection in recovered patients, and mosquitoes' potential is necessary to be prepared against future emergence/resurgence of diseases caused by coronaviruses.

\section{ACKNOWLEDGEMENTS}

We would like to thank Dr. B N Nagpal for his encouragement and support for this work. We are grateful to Dr. Sucheta Shah Mehta for her advice and her useful input.

\section{Conflict of interest}

The authors declare that they have no conflict of interest.

\section{REFERENCES}

1. Agnihotri, D., Singh, Y., Batra, K., Jain, V. K., Kumar, A., Kumar, T. and Maan, S. (2018). Molecular Detection Based Epidemiology of Canine Parvovirus and Canine Coronavirus Infection in Diarrheic Dogs in Haryana. Journal of Animal Research, 8(3), 367-374.

2. Bai, N. (2020). Why Experts Are Urging Social Distancing to Combat Coronavirus Outbreak [Last updated March 14, 2020, last cited April 20, 2020]. Retrieved from https:// www.ucsf.edu/news/2020/03/416906/why-experts-areurging-social-distancing-combat-coronavirus-outbreak

3. Bai, Y., Yao, L., Wei, T., Tian, F., Jin, D. Y., Chen, L. and Wang, M. (2020). Presumed asymptomatic carrier transmission of COVID-19. Journal of the American Medical Association, 323(14), 1406-1407.

4. Bakrania, K., Russell, R., and Falkous, C. (2020). Covid19 mortality rates by age and gender: why is the disease killing more men than women?

5. Behera, M., Panda, S. K., Sahoo, P. K., Acharya, A. P., Patra, R. C., Das, S. and Pati, S. (2015). Epidemiological study of canine parvovirus infection in and around Bhubaneswar, Odisha, India. Veterinary world, 8(1), 33-36. https://doi.org/10.14202/vetworld.2015.33-37

6. Beiu, C., Mihai, M., Popa, L., Cima, L., and Popescu, M. N. (2020). Frequent hand washing for COVID-19 prevention can cause hand dermatitis: management tips. Cureus, 12(4), e7506. https://doi.org/10.7759/cureus.7506

7. Bhatia, S. and Devulapalli, S. (2020). Mapped: The spread of coronavirus across India's districts. [Last updated April 19, 2020, last cited April 20, 2020]. Retrieved from https://www.livemint.com/news/india/mapped-thespread-of-coronavirus-across-india-s-districts-1158717 9250870

8. Bhattacharjee, S. (2020). Statistical investigation of relationship between spread of coronavirus disease (COVID19) and environmental factors based on study of four mostly affected places of China and five mostly affected places of Italy. arXiv preprint arXiv:2003.11277.
9. Cavanagh, G. and Wambier, C. G. (2020). Rational hand hygiene during the coronavirus 2019 (COVID-19) pandemic. Journal of the American Academy of Dermatology, 82(6), e211. https://doi.org/10.1016/j.jaad.2020.03.090

10. Chan-Yeung, M. and Xu, R. H. (2003). SARS: Epidemiology. Respirology, 8, 9-14. https://doi.org/10.1046/j.14401843.2003.00518.x

11. Chen, J. (2020). Pathogenicity and transmissibility of 2019 -nCoV-a quick overview and comparison with other emerging viruses. Microbes and infection, 22, 69-75. https://doi.org/10.1016/j.micinf.2020.01.004

12. Chen, L., Xiong, J., Bao, L. and Shi, Y. (2020). Convalescent plasma as a potential therapy for COVID-19. The Lancet Infectious Diseases, 20(4), 398-400. https:// doi.org/10.1016/s1473-3099(20)30141-9

13. Davey, S., Davey, A. and Jain, R. (2020). Impact of Social Distancing on Curtailing COVID 2019 Epidemic in India: A Systematic Review by SWOT Analysis Approach. Epidemiology International, 5(1), 44-49. https:// doi.org/10.24321/2455.7048.202009

14. Dhama, K., Sharun, K., Tiwari, R., Sircar, S., Bhat, S., Malik, Y. S., and Rodriguez-Morales, A. J. (2020). Coronavirus disease 2019-COVID-19. Clinical Microbiology Reviews, 33(4), 1-48. https://doi.org/10.20944/ preprints202003.0001.v1

15. Dutta, A. K. (2020). Vaccine Against Covid-19 DiseasePresent Status of Development. The Indian Journal of Pediatrics, 87, 810-817. https://doi.org/10.1007/s12098020-03475-w

16. Esposito, S., Principi, N., Leung, C. C. and Migliori, G. B. (2020). Universal use of face masks for success against COVID-19: evidence and implications for prevention policies. European Respiratory Journal, 55(6), 2001260. https://doi.org/10.1183/13993003.01260

17. Fang, Y., Zhang, H., Xie, J., Lin, M., Ying, L., Pang, P. and Ji, W. (2020). Sensitivity of chest CT for COVID-19: comparison to RT-PCR. Radiology, 296, 115-117. https:// doi.org/10.1148/radiol.2020200432

18. Fauver, J. R., Gendernalik, A., Weger-Lucarelli, J., Grubaugh, N. D., Brackney, D. E., Foy, B. D. and Ebel, G. D. (2017). The use of xenosurveillance to detect human bacteria, parasites, and viruses in mosquito bloodmeals. The American Journal of Tropical Medicine and Hygiene, 97 (2), 324-329. https://doi.org/10.4269/ajtmh.17-0063

19. Guo, Y. R., Cao, Q. D., Hong, Z. S., Tan, Y. Y., Chen, S. D., Jin, H. J. and Yan, Y. (2020). The origin, transmission and clinical therapies on coronavirus disease 2019 (COVID-19) outbreak-an update on the status. Military Medical Research,7(1), 1-10. https://doi.org/10.1186/ s40779-020-00240-0

20. Hansa, A., Rai, R. B., Wani, M. Y. and Dhama, K. (2012a). Patholology and diagnosis of corona virus infection in bovine. Indian Journal of Veterinary Pathology, 36 (2), 129-135.

21. Hansa, A., Rai, R. B., Wani, M. Y. and Dhama, K. (2012b). ELISA and RT-PCR based detection of bovine coronavirus in northern India. Asian Journal of Animal and Veterinary Advances, 7(11), 1120-1129. https:// doi.org/10.3923/ajava.2012.1120.1129

22. Hellewell, J., Abbott, S., Gimma, A., Bosse, N. I., Jarvis, C. I., Russell, T. W. and Eggo, R. M. (2020). Feasibility of controlling COVID-19 outbreaks by isolation of cases and 
contacts. The Lancet Global Health, 8(4), 488-196. https:// doi.org/10.1016/s2214-109x(20)30074-7

23. Hilgenfeld, R. and Peiris, M. (2013). From SARS to MERS: 10 years of research on highly pathogenic human coronaviruses. Antiviral Research, 100(1), 286-295. https://doi.org/10.1016/j.antiviral.2013.08.015

24. ICMR (2020a). Covid-19 Vaccine, ICMR, operational guidelines, updated on 28 December 2020. Retrieved from https://www.mohfw.gov.in/pdf/COVID19VaccineOG1 11Chapter16.pdf

25. ICMR (2020b). National Taskforce for COVID-19 Advisory on the use of hydroxy-chloroquine as prophylaxis for SARS-CoV-2 infection. Indian Council of Medical Research [Last updated March 22, 2020, Last cited April 25 , 2020]. Retrieved from https://www.mohfw.gov.in/pdf/ AdvisoryontheuseofHydroxychloroquinasprophylaxisforSARSCoV2infection.pdf.

26. Jha, V., Dinesh, T. A. and Nair, P. (2020). Are we Ready for Controlling Community Transmission of COVID 19 in India?. Epidemiology International, 5(1), 10-13. https:// doi.org/10.24321/2455.7048.202003

27. Jiang, F., Deng, L., Zhang, L., Cai, Y., Cheung, C. W. and Xia, Z. (2020). Review of the clinical characteristics of coronavirus disease 2019 (COVID-19). Journal of General Internal Medicine, 7, 1-5. https://doi.org/10.1007/s11606020-05762-w

28. Jiang, J., and Luo, L. (2020). Influence of population mobility on the novel coronavirus disease (COVID-19) epidemic: based on panel data from Hubei, China. Global Health Research and Policy, 5, 1-10. https:// doi.org/10.1186/s41256-020-00151-6

29. Junglen, S., Kurth, A., Kuehl, H., Quan, P. L., Ellerbrok, H., Pauli, G., and Leendertz, F. H. (2009). Examining landscape factors influencing relative distribution of mosquito genera and frequency of virus infection. Ecohealth, 6 (2), 239-249. https://doi.org/10.1007/s10393-009-0260-y

30. Kaneda, T. and Greenbaum, C. (2020). How Demographic Changes Make Us More Vulnerable to Pandemics Like the Coronavirus. Population Reference Bureau [Last updated April 13, 2020, last cited April 21, 2020]. Retrieved from https://www.prb.org/how-demographic-changesmake-us-more-vulnerable-to-pandemics-like-thecoronavirus/.

31. Kuwata, R., Satho, T., Isawa, H., Yen, N. T., Phong, T. V., Nga, P. T., and Sawabe, K. (2013). Characterization of Dak Nong virus, an insect nidovirus isolated from Culex mosquitoes in Vietnam. Archives of Virology, 158(11), 2273-2284. https://doi.org/10.1007/s00705-013-1741-4

32. Lan, L., Xu, D., Ye, G., Xia, C., Wang, S., Li, Y., and Xu, H. (2020). Positive RT-PCR test results in patients recovered from COVID-19. Journal of American Medical Association, 323(15), 1502-1503. https://doi.org/10.1001/ jama.2020.2783

33. Lauer, S. A., Grantz, K. H., Bi, Q., Jones, F. K., Zheng, Q., Meredith, H. R., and Lessler, J. (2020). The incubation period of coronavirus disease 2019 (COVID-19) from publicly reported confirmed cases: estimation and application. Annals of Internal Medicine, 172(9), 577-582. https:// doi.org/10.7326/m20-0504

34. Li, Q., Guan, X., Wu, P., Wang, X., Zhou, L., Tong, Y., and Feng, Z. (2020a). Early transmission dynamics in Wuhan, China, of novel coronavirus-infected pneumo- nia. New England Journal of Medicine, 382, 1199-1207. https://doi.org/10.3410/f.737281536.793571806

35. Li, T., Liu, Y., Li, M., Qian, X. and Dai, S. Y. (2020b). Mask or no mask for COVID-19: A public health and market study. PloS one, 15(8), e0237691. https:// doi.org/10.1371/journal.pone.0237691

36. Liu, Y., Yan, L. M., Wan, L., Xiang, T. X., Le, A., Liu, J. M. and Zhang, W. (2020). Viral dynamics in mild and severe cases of COVID-19. The Lancet Infectious Diseases, 20 (6), 656-657. https://doi.org/10.1016/s1473-3099(20) $30232-2$

37. Lotfinejad, N., Peters, A., and Pittet, D. (2020). Hand hygiene and the novel coronavirus pandemic: the role of healthcare workers. The Journal of hospital infection, 105 (4): 776-777. https://doi.org/10.1016/j.jhin.2020.03.017

38. Lu, G., Wang, Q. and Gao, G. F. (2015). Bat-to-human: spike features determining 'host jump' of coronaviruses SARS-CoV, MERS-CoV, and beyond. Trends in Microbiology, 23(8), 468-478. https://doi.org/10.1016/ j.tim.2015.06.003

39. Lu, R., Zhao, X., Li, J., Niu, P., Yang, B., Wu, H. and Tan, W. (2020). Genomic characterisation and epidemiology of 2019 novel coronavirus: implications for virus origins and receptor binding. The Lancet, 395, 565-574. https:// doi.org/10.1016/s0140-6736(20)30251-8

40. Malhotra, B., Swamy, M. A., Reddy, P. J. and Gupta, M. L. (2016). Viruses causing severe acute respiratory infections (SARI) in children $\leq 5$ years of age at a tertiary care hospital in Rajasthan, India. The Indian Journal of Medical Research, 144(6), $877 . \quad$ https://doi.org/10.4103/ ijmr.ijmr_22_15

41. Malik, Y. S., Sircar, S., Bhat, S., Sharun, K., Dhama, K., Dadar, M. and Chaicumpa, W. (2020). Emerging novel coronavirus (2019-nCoV) current scenario, evolutionary perspective based on genome analysis and recent developments. Veterinary Quarterly, 40(1), 68-76. https:// doi.org/10.1080/01652176.2020.1727993

42. Marwah, A. and Marwah, P. (2020). Coronavirus (COVID19): A protocol for prevention, treatment and control. Journal of Applied and Natural Science, 12(2), 119123. https://doi.org/10.31018/jans.vi.2269

43. Manavi K. (2021). India's Covid-19 vaccine rollout needs to address hesitancy to truly take off. Quartz India. [Last updated January 20, 2021, last cited January 20, 2021]. Retrieved from Indians hesitant to get Covaxin, Covishield Covid-19 vaccines, Quartz India (qz.com).

44. Mandal, S., Bhatnagar, T., Arinaminpathy, N., Agarwal, A., Chowdhury, A., Murhekar, M., and Sarkar, S. (2020). Prudent public health intervention strategies to control the coronavirus disease 2019 transmission in India: A mathematical model-based approach. The Indian Journal of Medical Research, 151, 190-195. https://doi.org/10.4103/ ijmr.ijmr_504_20

45. Mecenas, P., Bastos, R. T. R. M., Vallinoto, A. C. R. and Normando, D. (2020). Effects of temperature and humidity on the spread of COVID-19: A systematic review. PLoS One, 15(9), 1-19. https://doi.org/10.1371/journal.po ne. 023833

46. Memish, Z. A., Mishra, N., Olival, K. J., Fagbo, S. F., Kapoor, V., Epstein, J. H. and Lipkin, W. I. (2013). Middle East respiratory syndrome coronavirus in bats, Saudi Arabia. Emerging Infectious Diseases, 19(11), 1819-1823. 
https://doi.org/10.3201/eid1911.131172

47. MOHFW (2020). Standard Operating Procedure for Passenger Movement post Disembarkation [Last updated March 19, 2020 and last cited March 30, 2020]. Retrieved from https://www.mohfw.gov.in/pdf/SOPQuarant ineofPassengers.pdf.

48. Naik, S., Paleja, A., Mahajan, M., Ramachandran, N., Dixit, S., Matthan, R. and Kotasthane, P. (2020). A COVID -19 Vaccine Deployment Strategy for India. Indian Public Policy Review, 1(2), 42-58.

49. Paraskevis, D., Kostaki, E. G., Magiorkinis, G., Panayiotakopoulos, G., Sourvinos, G., and Tsiodras, S. (2020). Full-genome evolutionary analysis of the novel corona virus (2019-nCoV) rejects the hypothesis of emergence as a result of a recent recombination event. Infection, Genetics and Evolution, 79, 104212. https://doi.org/10.1016/j.meegid.2020.104212

50. Parikh, P. A., Shah, B. V., Phatak, A. G., Vadnerkar, A. C., Uttekar, S., Thacker, N., and Nimbalkar, S. M. (2020). COVID-19 pandemic: knowledge and perceptions of the public and healthcare professionals. Cureus, 12(5), e8144. https://doi.org/10.7759/cureus.8144

51. Rai, R. B., Hansha, A., Rai, S., Singh, B., Kumar, H., Singh, A. K. and Dhama, K. (2011). Prevalence of rota and coronavirus infections in calves of Barabanki and Raebareli districts of Uttar Pradesh. Indian Journal of Veterinary Pathology, 35(1), 73-74.

52. Roy, A., Parida, S. P. and Bhatia, V. (2020). Role of disinfection and hand hygiene: a COVID-19 perspective. International Journal of Community Medicine and Public Health, 7(7), 2845-2849. http://dx.doi.org/10.18 203/2394-6040.ijcmph20203025

53. Rundle, C. W., Presley, C. L., Militello, M., Barber, C., Powell, D. L., Jacob, S. E. and Dunnick, C. A. (2020). Hand hygiene during COVID-19: recommendations from the American contact dermatitis society. Journal of the American Academy of Dermatology, 83(6), 1730-1737. https://doi.org/10.1016/j.jaad.2020.07.057

54. Sardar, T., Nadim, S. S., Rana, S. and Chattopadhyay, J. (2020). Assessment of lockdown effect in some states and overall, India: A predictive mathematical study on COVID19 outbreak. Chaos, Solitons \& Fractals, 139, 110078. https://doi.org/10.1016/j.chaos.2020.110078

55. Singer, D. R. (2020). A new pandemic out of China: the Wuhan 2019-nCoV coronavirus syndrome. Health Policy and Technology, 9(1), 1-2. https://doi.org/10.1016/j.hlp t.2020.02.001

56. Singhal, T. (2020). A review of coronavirus disease-2019 (COVID-19). The Indian Journal of Pediatrics, 1-6. https:// doi.org/10.1007/s12098-020-03263-6

57. Sonawane, A. A., Shastri, J. and Bavdekar, S. B. (2019). Respiratory pathogens in infants diagnosed with acute lower respiratory tract infection in a tertiary Care Hospital of Western India Using Multiplex Real Time PCR. The Indian Journal of Pediatrics, 86(5), 433-438. https:// doi.org/10.1007/s12098-018-2840-8

58. Soutik, B. (2020). Covid vaccine: India expects to 'begin vaccination in January'. BBC News, 2020 [Last updated December 18, 2020, last cited December 20, 2020]. Retrieved from Covid vaccine: India expects to 'begin vaccination in January' - BBC News.
59. Thurackal, B. J., Chith, E. N. and Mascarenhas, P. (2020). The outbreak of novel coronavirus in India: Psychological impact. SSRN Journal, pp 1-18. https://dx.doi.org/10.2 139/ssrn.3562062

60. Tregoning, J. S., Brown, E. S., Cheeseman, H. M., Flight, K. E., Higham, S. L., Lemm, N. M., and Pollock, K. M. (2020). Vaccines for COVID-19. Clinical \& Experimental Immunology, 202(2), 162-192.

61. Wadhawan, D. A. (2020). Rajasthan: With 19 coronavirus patients, including 15 medics, Bhilwara continues to battle virus. India today [Last updated March 26, 2020 and last cited May 1, 2020]. Retrieved from https:// www.indiatoday.in/india/story/rajasthan-18-coronaviruspatients-including-15-doctors-bhilwara-continues-battlecovid-19-1660064-2020-03-26.

62. Wang, T., Du, Z., Zhu, F., Cao, Z., An, Y., Gao, Y. and Jiang, B. (2020a). Comorbidities and multi-organ injuries in the treatment of COVID-19. The Lancet, 395(10228), e52. https://doi.org/10.1016/s0140-6736(20)30558-4

63. Wang, W., Tang, J. and Wei, F. (2020b). Updated understanding of the outbreak of 2019 novel coronavirus (2019 $\square \mathrm{nCoV}$ ) in Wuhan, China. Journal of Medical Virology, 92 (4), 441-447. https://doi.org/10.1002/jmv.25689

64. World Health Organization (2020). Coronavirus disease 2019 (COVID-19): situation report, 54. World Health Organization. https://apps.who.int/iris/handle/10665/331478

65. Wu, X., Nethery, R. C., Sabath, B. M., Braun, D. and Dominici, F. (2020). Exposure to air pollution and COVID19 mortality in the United States. medRxiv. https:// doi.org/10.1101/2020.04.05.20054502.

66. Yadav, S., Kumar, V., Sharma, M., Mishra, N. P. and Khan, W. (2020). An Overview of Analysis on The Pandemic Factors of Covid-19. International Journal of Multidisciplinary Sciences and Advanced Technology, 1, 55-66.

67. Yan, Y., Chen, H., Chen, L., Cheng, B., Diao, P., Dong, L., and Li, H. (2020). Consensus of Chinese experts on protection of skin and mucous membrane barrier for health $\square$ care workers fighting against coronavirus disease 2019. Dermatologic Therapy, 33(4), e13310. https://doi.org/1 $0.1111 /$ dth. 13310

68. Ye, Z. W., Yuan, S., Yuen, K. S., Fung, S. Y., Chan, C. P., and Jin, D. Y. (2020). Zoonotic origins of human coronaviruses. International Journal of Biological Sciences, 16 (10), 1686-1697. https://doi.org/10.7150/ijbs.45472

69. Zhang, C., Zheng, W., Huang, X., Bell, E. W., Zhou, X. and Zhang, Y. (2020). Protein structure and sequence reanalysis of 2019-nCoV genome refutes snakes as its intermediate host and the unique similarity between its spike protein insertions and HIV-1. Journal of Proteome Research, 19(4), 1351-1360. https://doi.org/10.1021/ acs.jp roteome.0c00129

70. Zhou, D., Zhang, P., Bao, C., Zhang, Y. and Zhu, N. (2020). Emerging understanding of etiology and epidemiology of the novel coronavirus (COVID-19) infection in Wuhan, China. https://doi.org/10.20944/preprints20200 2.0283.v1

71. Zhu, N., Zhang, D., Wang, W., Li, X., Yang, B., Song, J. and Tan, W. (2020). A novel coronavirus from patients with pneumonia in China, 2019. New England Journal of Medicine, 382:727-733. https://doi.org/10.1056/nejmoa2 001017 